\title{
UMA EXPERIÊNCIA DE INTERVENÇÃO EM UM PROJETO CULTURAL: O PSICÓLOGO E A DEFESA DOS DIREITOS HUMANOS NAS INSTITUIÇÕES SOCIOEDUCATIVAS
}

\author{
Fabio Montalvão Soares ${ }^{\star}$
}

\begin{abstract}
Resumo
$O$ artigo discute, a partir da experiência da realização do Projeto Oficinas Culturais do AfroReggae no Degase, a atuação do psicólogo num projeto cultural direcionado às instituições socioeducativas. Na problematização a respeito da inserção profissional nesse contexto, tece considerações sobre o estatuto da intervenção, baseando-se na tecnologia de mediação de conflitos do Grupo Cultural AfroReggae como exemplo de dispositivo utilizado estrategicamente para esse fim. O papel do psicólogo caracteriza-se, nas relações com os jovens em conflito com a lei, como o de facilitador dos processos coletivos e do plano político, proporcionando a construção de uma rede de gestão de atividades em prol da defesa dos seus direitos fundamentais.

Palavras-chave: dispositivo de intervenção; projeto cultural; mediação de conflitos; direitos humanos.

\section{AN EXPERIENCE OF INTERVENTION IN A CULTURAL PROJETCT: THE PSYCHOLOGIST AND THE DEFENSE OF HUMAN RIGHTS IN SOCIAL-EDUCATIONAL INSTITUTIONS.}

\begin{abstract}
Based on the project "Oficinas Culturais do AfroReggae no Degase", the article discusses the possibilities of the psychologist practice in a cultural project developed in social-educational institutions. As to the professional inclusion in this context, this paper considers the status of the intervention, based on the conflict mediation technology used by the cultural group AfroReggae as an example of a device strategically used for this purpose. Concerning the relationship with the youngsters in conflict with the law, the role of the psychologist is that of a facilitator of the collective process and the political level, providing the construction of a network of activities and defense of their fundamental rights.

Keywords: Status of the intervention. Cultural project. Conflict mediation. Human rights.

\footnotetext{
^ Psicólogo. Mestre em Psicologia pela Universidade Federal Fluminense. Psicólogo do Grupo Cultural AfroReggae. Tutor do Curso de Atualização para Conselheiros Tutelares e dos Direitos da Criança e do Adolescente (Programa de Educação a Distância da Escola Nacional de Saúde Pública/ Fundação Oswaldo Cruz).

E-mail: fmontalvaosoares@yahoo.com.br
} 


\section{INTRODUÇão}

A intervenção do psicólogo no contexto de um projeto cultural de cunho social, aplicado nos estabelecimentos institucionais responsáveis pela execução de medidas socioeducativas no Rio de Janeiro, é o objeto de um campo de pesquisa recente. Este emerge no atual conjunto de ações que visam contribuir para a reinserção social dos jovens em conflito com a lei em consonância com a legislação garantidora dos direitos da criança e do adolescente vigente no país. O projeto em questão é o "Projeto Oficinas Culturais do AfroReggae no Degase", fruto de uma parceria que envolve o Grupo Cultural AfroReggae (GCAR), a Secretaria Estadual de Educação (SEEDUC) e o Departamento de Ações Socioeducativas (DEGASE), com o objetivo de oferecer oficinas culturais em várias modalidades artísticas para os jovens em cumprimento de medida socioeducativa de internação.

A implantação de oficinas culturais nas unidades do DEGASE segue a tendência de complementar as ações educativas desenvolvidas na instituição, considerando o capítulo IV do Estatuto da Criança e do Adolescente que contempla o direito fundamental do acesso à educação e à cultura. Valorizamos nesse aspecto, o item V do artigo 54 do mesmo capítulo, que trata do "acesso aos níveis mais elevados do ensino, da pesquisa e da criação artística, segundo a capacidade de cada um" (BRASIL, 2007, p. 20). Já o artigo 58 do Estatuto estabelece que "no processo educacional respeitar-se-ão os valores culturais, artísticos e históricos próprios do contexto social da criança e do adolescente, garantindo-lhes a liberdade da criação e o acesso às fontes de cultura" (BRASIL, 2007, p. 21). Mais do que contribuir para a simples distração ou lazer do seu público-alvo, as oficinas culturais fundamentam-se numa proposta político-pedagógica que contempla esse direito básico, proporcionando aos jovens o contato com elementos fundamentais de sua realidade sociocultural e incentivando o desenvolvimento de novas metodologias baseadas no trabalho artístico. Nesse sentido, as oficinas vêm obtendo êxito ao desenvolver um amplo canal de interlocução com seus alunos.

O trabalho realizado em parceria com as escolas sediadas nas unidades tem possibilitado o cumprimento desta prerrogativa, proporcionando, para além do aprendizado das modalidades artísticas, a construção de uma rede dialógica entre os jovens em cumprimento de medida socioeducativa. Através da tecnologia de mediação de conflitos utilizada pelo GCAR, as oficinas culturais promovem oportunidades de criação de novas referências e valores em prol do pleno exercício da cidadania e da conquista da autonomia política, se constituindo como espaços coletivos privilegiados. Desse modo elas possibilitam aos participantes uma experiência inovadora com o plano legitimador das relações de poder que atravessam seu cotidiano e o da instituição. A consolidação de grupos em torno das atividades culturais tem estimulado a criação de um espaço legítimo de reinvenção das normas, assim como o processo de gestão participativa das atividades, contribuindo para explicitar a dinâmica de funcionamento das relações institucionais em jogo. Valorizando a reflexão sobre as escolhas dos jovens e suas implicações, as oficinas vêm produzindo, através das atividades culturais, novas experiências de subjetivação. Tal fato transparece no processo de assimilação e produção de novos valores 
por parte dos jovens participantes, contribuindo para sua formação cidadã e para a mudança de perspectiva quanto aos fatores associados, por exemplo, à opção pela criminalidade, rompendo-se, em alguns casos, o círculo vicioso da reincidência no ato infracional e o retorno ao sistema socioeducativo.

É importante esclarecer que a perspectiva de uma opção está associada a uma série de atravessamentos históricos, políticos, sociais, culturais e econômicos, com o cuidado de não cairmos em um discurso de produção social do negativo (RAUTER, 2003), de estigmatização pela naturalização do ato infracional, ou de uma sujeição criminal (MISSE, 2010) ${ }^{1}$. Castro \& Guareschi (2008) apontam, por exemplo, que os adolescentes e seus familiares significam e são subjetivados pelo discurso da mídia, da sociedade contemporânea e do conhecimento dito técnico, os quais depositam na família a causa dos males das crianças e dos jovens. Nesse sentido, existe uma espiral de auto culpabilização e responsabilização que se processa na produção incessante dos discursos estigmatizantes e excludentes. Estes por sua vez se tornam oficializados pelo fausto judiciário e naturalizados pelos próprios sujeitos em conflito com a lei: "Em contrapartida, observa-se a aceitação e submissão ao papel normativo representado pela figura de autoridade do Juiz. $\mathrm{O}$ ato infracional é visto com um ato 'fora da lei', pelo qual o próprio adolescente admite ser penalizado e castigado”. (CASTRO; GUARESCHI, 2008, p. 204).

Consequentemente, essa experiência no âmbito das oficinas sugere uma relação entre a tecnologia de mediação de conflitos e a emergência do plano coletivo no qual as relações de poder podem ser percebidas e reinventadas numa perspectiva diferenciada pelos participantes, constituindo-se um elemento importante na construção de dispositivos de intervenção.

\section{Contexto}

O AfroReggae é uma organização não governamental conhecida internacionalmente por seu trabalho artístico e social. Surgiu em 1993, inicialmente em torno do jornal AfroReggae Notícias, um veículo de informação que visava à valorização e à divulgação da cultura negra e tornou-se uma das maiores referências de prática sociocultural na cidade do Rio de Janeiro. A missão da ONG é a de promover a inclusão e a justiça social, utilizando a arte, a cultura afro-brasileira e a educação como ferramentas para a criação de pontes que unam as diferenças e sirvam de alicerces para a sustentabilidade e o exercício da cidadania. Todas as atividades realizadas são voltadas para a promoção dos valores culturais dos jovens e sua capacidade de ação social. Seus núcleos comunitários têm por característica comum estar inseridos em locais onde se constatam altos níveis de violência, criminalidade, vulnerabilidade e risco social por diversos motivos, tais como a pobreza, a falta de oportunidades sociais, as violações impostas pelo narcotráfico (RAMOS, 2007; MEIRELLES; GOMEZ, 2009) etc. Ampliar as possibilidades de escolha, romper com a marginalização decorrente da pobreza e do preconceito, abrir novos horizontes para os moradores das comunidades pobres do Rio de Janeiro são suas principais metas. 
Em 2007 o GCAR iniciou, através da sua coordenação de projetos especiais, uma série de ações promotoras da valorização da cultura negra e da cidadania, levando suas oficinas culturais para unidades prisionais de alguns estados no Brasil. Barros, Waiselfisz e Roseno (2006), baseados em dados da SEDH, afirmam que o índice de jovens negros em privação de liberdade é superior a $60 \%$. Lima (2004) ressalta que a maioria da população pobre é composta por negros e que o comportamento desta é historicamente criminalizado, sendo que estes recebem tratamento penal mais severo para atos iguais aos cometidos por brancos.

O trabalho do AfroReggae, surge segundo RAMOS (2007), no movimento de grupos de jovens negros de favelas organizados em torno de experiências culturais e que "esses grupos tematizam a violência e procuram construir novos estereótipos que dissociem os jovens de periferia das imagens de criminalidade". (RAMOS, 2007. p. 1303). Nesse movimento a ONG elabora um projeto baseado em ações culturais direcionado ao sistema socioeducativo. Dados estatísticos demonstram, por exemplo, que o Rio de Janeiro é um dos estados que concentram o maior número de jovens em cumprimento de medida socioeducativa de internação (SILVA; GUERESI, 2003; ROCHA, 2002) refletindo as estatísticas nacionais. ${ }^{2}$ Sensível a essa realidade foi criado um projeto piloto, em parceria, na época, com a Secretaria Especial de Direitos Humanos do Governo Federal. A partir de 2008 é celebrada uma nova parceria, agora com a SEEDUC, visando à continuidade do projeto no DEGASE. Cabe salientar que no mesmo ano esta secretaria incorporou o Departamento de Ações Socioeducativas como pasta subordinada na hierarquia do governo. Nesse novo convênio foi instituída pela ONG, uma equipe técnica social exclusiva para o projeto, contando com a participação de um assistente social, um psicólogo e uma pedagoga, que iniciam um trabalho de planejamento das ações, de criação de instrumentos de avaliação e de pesquisa e a elaboração de um plano pedagógico para atender exclusivamente às necessidades das oficinas no contexto da instituição parceira.

A partir desse período o GCAR vem realizando oficinas culturais nas seguintes unidades de aplicação de medidas socioeducativas de internação: Escola João Luis Alves (EJLA), com as modalidades de percussão, teatro e grafite; Educandário Santo Expedito (ESE), com a modalidade de percussão; e Educandário Santos Dumont (ESD), unidade feminina de internação e internação provisória com oficinas de percussão e teatro. Devemos mencionar que em 2008 foram oferecidas aulas de teatro e grafite para alunos em cumprimento de medida socioeducativa de semiliberdade oriundos dos CRIAAD's (antigos CRIAM's) no Centro de Capacitação Profissional (CECAP). Estas foram extintas pelo fato de a direção do DEGASE entender que a referida unidade deveria abraçar somente cursos profissionalizantes, remanejando as oficinas do AfroReggae somente para as unidades de internação. No ESE o trabalho é recente, tendo sido iniciado no segundo semestre de 2009 e conta ainda com a implantação de uma oficina de esportes coletivos nas modalidades de futsal e basquete de rua. Essa oficina, embora se diferencie do perfil artístico comum às demais modalidades do projeto, baseou-se na mesma proposta metodológica a elas aplicada. 
O objetivo do projeto é a formação de multiplicadores do trabalho cultural do GCAR. O conceito de multiplicador engloba o desenvolvimento de novas perspectivas sociais e culturais e a geração de uma rede de relações, na qual os jovens possam adquirir consciência de suas possibilidades e responsabilidades, tornando-se protagonistas das transformações operadas em sua realidade. Nesse cenário, uma reflexão sobre o papel do psicólogo e da equipe técnica social como um todo surgiu num panorama de organização geral das prioridades que o projeto reclamava. Tal reflexão se deu em meio a uma inserção considerada "flutuante", sem atribuições específicas e orientadas, principalmente, na otimização dos mecanismos garantidores da participação dos jovens. Atuamos em diversas frentes, contornando os obstáculos que impediam o pleno desenvolvimento do trabalho e esbarrando no que BARROS; WAISELFISZ; ROSENO (2006) denominam como "condições inóspitas" no plano da atuação profissional. ${ }^{3} \mathrm{O}$ grande desafio foi o da criação de uma forma diferenciada de atuação, utilizando os elementos disponíveis no cenário político institucional para a elaboração de estratégias de intervenção que fortalecessem as diretrizes estabelecidas.

No entanto, não poderíamos nos restringir ao mero perfil de gestores das atividades. Pensar a atuação profissional em um projeto cultural de cunho social, realizado dentro das unidades do DEGASE, obriga-nos a definir o plano político como eixo prioritário na intervenção. E ao definirmos tal prioridade, remetemo-nos, sobretudo, à defesa e à manutenção dos direitos fundamentais desses jovens, entendendo que, em função de sua caracterização como instituição total (GOFFMAN, 1961) e disciplinar (FOUCAULT, 1975), o sistema socioeducativo promove, no campo micropolítico, formas peculiares de assujeitamento, despersonalização e exclusão dos seus atores ${ }^{4}$. Não devemos, portanto, desconsiderar os atravessamentos e as implicações de uma longa tradição histórica na qual os jovens, caracterizados como menores infratores, delinquentes, dentre tantos outros rótulos estigmatizadores, eram submetidos a um sistema excludente, violador dos direitos humanos e regido pela lógica prisional. Ao atuar no DEGASE hoje, devemos exaltar as transformações decisivamente importantes ocorridas para a mudança desse cenário. Porém, cabe salientar que: "os governos têm se mostrado um pouco mais inclinados a ouvir esse jovem e sua família. Entretanto, o que se tem feito ainda está longe de chegar ao que entendemos como educativo, ou seja, condizente com o que é preconizado pelo ECA." (CUNHA; SALES; CANARIM, 2007, p. 38).

Com o desenrolar das atividades, o campo de atuação ia se delimitando em sintonia com uma transformação do status da intervenção, saindo esta da condição de simples operacionalização de mecanismos em prol da garantia de participação, em direção à elaboração de um dispositivo de intervenção como facilitador do processo de construção da rede com os jovens. Se inicialmente partimos da premissa de assegurar, por meio de nossas ações, o acesso dos jovens a nossas atividades, fato inclusive obstacularizado pelo contexto burocratizante da instituição parceira, a meta passou a ser o de garantir não só a participação, mas gestão coletiva das atividades, em vez destas serem diretivas e impostas aos alunos. Consequentemente, as oficinas tornaram-se um espaço catalisador das relações de poder em jogo naquele contexto. Estar desenvolvendo um trabalho 
no qual, para além de uma simples visão educativa, se propõe uma experiência de construção de valores políticos e éticos como referência concreta para seu público-alvo constituiu o grande desafio.

\section{O DESAFIO DA INTERVENÇ̃̃o}

A construção de estratégias de intervenção se deu mediante os impasses oriundos do contexto de trabalho. Nesse movimento a equipe técnica social do projeto se deparou com uma realidade diversa à do trabalho realizado em seus núcleos comunitários e mesmo nos projetos realizados no sistema prisional. Situações comuns ao sistema socioeducativo como a não liberação ou a retirada aleatória e não comunicada dos alunos das atividades, o remanejamento de jovens para a realização de outras atividades sem observância ao calendário e cronograma conjuntamente planejados, mostraram-se desafiadoras. Obstáculos como esses levaram a equipe a se adaptar ao novo contexto, uma vez que tais fatores afetavam diretamente o aproveitamento e a continuidade das ações. Procurávamos agir em parceria com as equipes técnicas das unidades e com suas escolas, adotando uma política de troca de informações e construindo estratégias de abordagens a serem aplicadas junto aos jovens, a fim de melhor compreender sua realidade e desconstruir o "olhar preconceituoso" presente no imaginário de alguns funcionários. Nesse particular, constatamos a existência de uma oposição entre os funcionários (especialmente os agentes de disciplina) e os jovens, conforme os apontamentos de Espíndula e Santos (2004). Os autores afirmam, por exemplo, que as representações sociais dos agentes caracterizam os adolescentes em conflito com a lei que cumprem pena em regime de privação de liberdade como diferenciados dos adolescentes ditos normais. A condição de infratores é justificada, na concepção dos agentes, por uma suposta "fraqueza" atribuída a esses adolescentes (ESPÍNDULA; SANTOS, 2004, p. 364).

O enfrentamento dessa problemática nos levou a pensar que uma proposta de intervenção nos remete a considerações sobre seu estatuto. Se lhe atribuíssemos o sentido positivista usual, estaríamos nos referindo a um conjunto de ações empreendidas por um especialista, para se modificar o plano das relações estabelecidas mediante uma demanda específica. Aqui os atores envolvidos ocupariam logicamente o lugar de passividade na condução do processo. Ou seja: se a intervenção se encaminhasse nessa direção, ela se limitaria a uma visão dos dispositivos como simples mecanismos utilizados pelo técnico no intuito de assegurar a participação dos jovens. Todo o trabalho seria assim verticalizado, com as diretrizes determinadas pelo especialista. No entanto, no sentido que propõe a Análise Institucional (LOURAU, 1970), a intervenção não se constitui por uma ação isolada atribuída a um profissional, mas no processo de autogestão das atividades que envolvem todos os atores, na perspectiva de um questionamento sobre as regras e as normas estabelecidas: "a fazer surgir na realidade concreta (na palavra dos atores e não numa formulação científica exterior à linguagem dos atores) o caráter dialético, simultaneamente positivo e negativo de todo agrupamento organizado" (COIMBRA, 1995, p. 61). Iniciado num movimento de confrontação com as normas estabelecidas, o processo transpassa essa dimensão e permite a 
emergência das condições que determinam seu suposto status apriorístico: "Portanto, a proposta da análise Institucional é a de que a autogestão se torne uma contra instituição, fazendo aparecer os elementos ocultos no sistema" (COIMBRA, 1995, p. 63). Por conseguinte, a autogestão torna-se um eixo fundamental na proposta de intervenção e, em função desse fato, consideramos como premissa básica a conquista da autonomia dos alunos nas oficinas, dando-lhes espaço para que pudessem participar verdadeiramente das decisões na condução do trabalho.

Durante as atividades, nas situações que envolviam algum jovem e eram consideradas problemáticas, registrávamos as ocorrências com o cuidado de não expor demasiadamente os envolvidos e evitando o desfecho fatídico do enfrentamento, posição comum na relação entre jovens e funcionários. Observamos ,evidentemente, a gravidade do fato, único fator que nos obrigaria a agir de modo contrário. Nesse momento, surge uma indagação sobre a justificativa para adotarmos essa postura. Devemos considerar que não se trata de uma posição protecionista para com os jovens, ou da inobservância de sua responsabilidade perante o ato cometido, para minimizar suas atitudes por considerá-los vítimas do sistema. Antes, nos casos de conflitos envolvendo os alunos, procurávamos conversar com eles de maneira ética e responsável, dentro do espaço coletivo das atividades, não compactuando com a situação irregular, mas encaminhando as discussões num plano em que os atores pudessem espontaneamente interagir e deliberar entre si, de igual para igual, em busca da resolução dos problemas. Isso só se tornou possível em função de uma abertura promovida, no âmbito das relações entre a equipe e os jovens, graças à tecnologia de mediação. Consequentemente ela tornou-se o ponto chave na construção da rede de relações e na consolidação da proposta de intervenção, no momento em que possibilitou diluir a resistência dos jovens a uma efetiva participação nas atividades e a equipe. Apresentaremos a seguir, algumas situações colhidas durante as oficinas a fim de melhor demonstrar nossas observações. Estas baseiam-se na experiência de inserção direta dos profissionais nas atividades, de acordo com a política de acompanhamento dos jovens, configurando-se como estudo de casos. Algumas informações obtidas durante o processo de entrevista individual dos jovens complementaram as observações na análise das ocorrências durante as reuniões de supervisão da equipe e fundamentam os relatos.

No início do trabalho, a oficina de teatro sofreu diversas interrupções abruptas protagonizadas por agentes que invadiam o espaço sem pedir licença, sob o pretexto de estarem cuidando da segurança. Numa dessas invasões, houve discussão entre os funcionários e os alunos, uma vez que estes consideravam tal atitude desrespeitosa, tanto para si próprios, quanto para os professores, desmobilizando a oficina e consumindo o tempo das atividades na resolução de um conflito desnecessário, em função do uso de truculência excessiva. Nesses casos, atuávamos junto a ambos os grupos para esvaziar a postura de enfrentamento.

Durante os preparativos para uma apresentação, os instrutores deram a sugestão de batizar o grupo de "Grupo de Teatro AfroReggae/DEGASE". Os alunos, em unanimidade, rejeitaram a proposta e ficaram apenas com nome "Grupo 
de Teatro AfroReggae", fato comum não só ao teatro mas a todas as oficinas, demonstrando sua visão negativa sobre a instituição e a percepção da dissimetria existente no plano das relações entre jovens e funcionários.

$\mathrm{O}$ aluno T., por exemplo, descumpriu a medida de semiliberdade. No entanto, continuou frequentando as oficinas realizadas no CECAP durante duas semanas, sendo constantemente advertido pelo diretor da unidade sobre sua situação. Nossa equipe e o diretor solicitavam constantemente ao jovem para que se reapresentasse no CRIAAD, onde cumpria sua medida, a fim de regularizar sua situação e não se configurar o descumprimento. O jovem, porém, mostrava-se aparentemente inflexível, embora desse sinais de rever sua posição. T. insistia em participar das aulas e só abandonou o grupo de vez após ser advertido de que, na próxima visita, seria detido, numa atitude de compreensão por parte da direção quanto ao quadro que se configurava.

Situações como essas, obtidas em nossa experiência, confirmam a manifestação, implícita ou explícita, de uma resistência pela maioria dos jovens em relação ao DEGASE, assim como o seu descrédito em relação às iniciativas empreendidas pela instituição (SOARES; RIBEIRO; DUARTE, 2009). O espaço onde se realizam as atividades não é, necessariamente, marcado por conflitos de ordem aberta ou manifesta. No entanto, a inserção pedagógica ou educativa nos apontou a existência de divergências e intolerâncias fundamentadas no etnocentrismo (DA MATTA, 1999) implícito, por exemplo, na construção das identidades dos grupos, galeras e outras formas de organização social relativas ao públicoalvo contemplado nas ações. Segundo o autor o conceito refere-se a uma visão do mundo em que o nosso próprio grupo é tomado como única referência e todos os outros são percebidos e pensados em função dos nossos valores, modelos e definições. Consequentemente, devemos considerar a manifestação de uma forma específica de olhar sobre os jovens e funcionários, construída nas relações entre eles. De acordo com Espíndula e Santos (2004), essas relações são estereotipadas e baseadas nas representações sociais oriundas da vida cotidiana na intuição, o que evidencia uma forma de etnocentrismo no plano institucional, presente, por exemplo, no antagonismo entre o grupo dos "agentes" e o dos "menores".

Situações como essas se davam não somente na relação entre esses dois grupos, mas igualmente entre os jovens e seus companheiros. Sobre esse assunto, Zaluar (2003) enfatiza, por exemplo, que guerras étnicas fundamentadas na disseminação das formas de violência molecular tendem a dissolver os espaços de dialogicidade e de trocas baseadas no respeito à alteridade e à diversidade. Perceber os efeitos dessa dissolução, assim como estabelecer ações eficazes a fim de combatê-la foi uma das metas do trabalho.

Tal fato nos levou a indagar sobre a concepção do sistema socioeducativo no imaginário desses jovens, gerando o seguinte questionamento: que tipo de relação foi estabelecida entre os alunos das oficinas e o GCAR e qual o seu diferencial, compreendendo-o como forte o suficiente para criar e manter vínculos capazes de levar um jovem em descumprimento de medida, como o do exemplo citado, à situação paradoxal de estar no espaço institucional de maneira irregular e 
sustentar, em detrimento dessa condição, o desejo de continuar frequentando as aulas? Indagamo-nos, ainda, sobre como essa relação diferenciada poderia contribuir para mudar qualitativamente o plano das relações entre jovens e funcionários, rompendo os antagonismos entre eles e transformando sua visão sobre a instituição. Um relato expressa essa realidade e nos fornece uma pista. Um adolescente revela ao membro da equipe técnica social durante uma entrevista: "Os cara do AfroReggae fecham com nóis" (Sic). Essa colocação salienta uma forma diferenciada de trato valorizado no plano da comunicação entre os jovens e a equipe do GCAR, principalmente com os instrutores responsáveis pelas oficinas.

Mas o que significa "fechar com nóis"? Com certeza não se trata de uma conivência com atitudes ilícitas, ou com a opção do jovem em justificar ou seguir o caminho da criminalidade. Essa frase sintetiza, na verdade, o sucesso da estratégia do GCAR em estabelecer um processo de aprendizagem de valores sociais, éticos e políticos, mediante o reconhecimento de que o GCAR tem para com o jovem uma posição de respeito à sua singularidade e à sua dignidade, mesmo não concordando com sua escolha. Tal estratégia é garantida por meio da tecnologia de mediação de conflitos desenvolvida pela ONG e foi o eixo fundamental na política de formação dos multiplicadores e da intervenção. No tocante à atuação do psicólogo, essa tecnologia tornou-se um instrumento importante na promoção de espaços dialógicos baseados na participação coletiva e no movimento de produção de novos modos de subjetivação.

\section{SOBRE A MEdiAÇão}

A mediação de conflitos caracteriza-se pela "interferência consentida de uma terceira parte em uma negociação ou em um conflito instalado, com poder de decisão limitado, cujo objetivo é conduzir a situação na direção de um acordo satisfatório construído voluntariamente pelas partes e, portanto, mutuamente aceitável, dadas as questões em disputa" (MOORE, 2002, p. 56). O mediador, no intuito de promover o diálogo e a cooperação entre os atores envolvidos, busca a via da negociação paritária e a solução não litigiosa de um problema. Nesse sentido, a técnica assume uma dimensão maior do que a da aplicação na solução de conflitos. Ela torna-se também uma forma de estimular, num processo participativo e autogestivo, a dialogicidade e o respeito à alteridade na promoção de espaços construídos de maneira democrática. Isto, por minimizar os antagonismos e as soluções arbitrárias, determinadas geralmente, segundo os interesses predominantes de um grupo autoritário pelo exercício da violência, ou pela coerção num viés totalitário. Outro benefício é o do favorecimento de um clima de cooperação e solidariedade entre os sujeitos, estimulado no decorrer do trabalho.

A metodologia utilizada pelo AfroReggae é diferenciada dessa perspectiva tradicional pelo fato de que, em se tratando desta, nas situações nas quais uma das partes é declaradamente violadora dos direitos humanos, a situação não pode ser objeto de uma ação mediadora e sim de ações em defesa dos direitos violados. Tal perspectiva se aplicaria, por exemplo, aos atores envolvidos no narcotráfico, com domínio estabelecido à base da violência sobre as comunidades onde o GCAR 
realiza seu trabalho. Segundo a diretriz tradicional da mediação, não haveria possibilidade de interlocução com esses atores, uma vez que eles promovem em suas práticas a violação constante dos direitos humanos. Portanto, de acordo com essa lógica, a perspectiva tradicional se aplicaria aos jovens em cumprimento de medida socioeducativa, considerando-os como sujeitos violadores em função do ato infracional cometido. Consequentemente, a medida socioeducativa se configuraria como ação de defesa dos direitos da parte violada e todas as ações envolvidas na medida assumiriam o aspecto de reparação de um ato violador cometido, obstacularizando uma paridade real no plano das relações com o jovem. Entretanto, o sujeito violador não deixa de ser um sujeito de direitos, num entendimento de que a medida em questão se configura, no panorama do Sistema de Garantia de Direitos, como uma ação de ressocialização. Segundo o item 9 do capítulo 3 do Sistema Nacional de Atendimento Socioeducativo: "o objetivo da medida é possibilitar a inclusão social de modo mais célere possível e, principalmente, o seu pleno desenvolvimento como pessoa" (SINASE, 2006, p. 30).

Outro fator importante na consolidação desse impasse é a lógica de ganho recíproco, fundamento da paridade entre as partes envolvidas e do processo como um todo. Nesse caso, a ação mediadora validaria, segundo a perspectiva tradicional, a posição do violador, ao estabelecer um regime de ganhos que contribuiria para reforçá-la, reconhecendo e legitimando a ação violenta. Porém, devemos considerar que mediar, de acordo com a proposta do AfroReggae, não é de nenhuma maneira favorecer a parte violadora, nem mesmo lhe fazer qualquer tipo de concessão nesse aspecto. Não se trata, portanto, de assumir uma posição de conivência com as ações ilegais da criminalidade. A mediação só se torna possível porque os integrantes do GCAR entendem que a posição violadora não obstaculariza a proposta do estabelecimento de algum diálogo. Este passa, todavia, a ter outro eixo de sustentação, constituindo-se um espaço diferenciado de interação entre os atores, no sentido de mobilizá-los em prol da manutenção de uma rede social de apoio às comunidades pobres e aos que não optaram pelo caminho da criminalidade. Portanto, se houve uma abertura no plano das relações entre a equipe GCAR e os jovens, esta foi em função do reconhecimento de uma legitimidade da participação desses atores e que o fato de estar cumprindo uma medida socioeducativa não os exclui da posição de sujeitos de direitos que o ECA busca consolidar.

Desse modo, a rede de relações não se garante segundo uma lógica de ganho para as partes envolvidas, como na perspectiva tradicional e que legitimaria a parte violadora. No caso da mediação promovida pelo AfroReggae, os atores são levados a reconhecer os danos e as consequências de suas ações e a pensar sobre a possibilidade de minimizar seus efeitos, principalmente sobre seus familiares e os demais membros da comunidade, grupo social por eles respeitado e altamente estimado em sua hierarquia de valores. Consequentemente há uma mudança qualitativa em relação aos ganhos envolvidos na relação. Estes não dizem respeito a qualquer concessão legitimadora da posição litigiosa adotada pelos jovens em 
conflito com a lei, mas envolve um benefício legítimo na implantação da rede social através do trabalho cultural e da possibilidade concreta de as pessoas realmente interessadas abandonarem o mundo do crime.

Para isso, o GCAR conta, preferencialmente nessa função, com a experiência de pessoas que tiveram envolvimento com o crime e estão atualmente mobilizadas pela defesa dos direitos humanos e pela inclusão social, interagindo nas zonas de risco dominadas pelo crime organizado e promovendo o apoio aos que desejam sair do círculo vicioso do tráfico e da criminalidade. Por ser parte integrante da realidade na qual atuam é que os mediadores do AfroReggae conseguem ter um alto poder de penetração nesses espaços. A experiência do projeto demonstrou, por exemplo, que os jovens costumavam se fechar ao discurso dos profissionais da instituição e mesmo dos técnicos do GCAR, abrindo-se a possibilidade de diálogo e troca mediante o reconhecimento de que os mediadores já cometeram algum tipo de ato infracional e tiveram passagem no sistema penal (SOARES; RIBEIRO; DUARTE, 2009). É em função, de viver integrado nas periferias, de conhecer de perto a realidade das comunidades carentes e principalmente, do saber por eles acumulado como fruto de suas experiências no crime organizado que os mediadores adquirem um alto poder de convencimento e são capazes de contornar a resistência manifesta pelos jovens, adquirindo deles respeito e confiabilidade.

Trata-se de uma capacidade de resolução denominada como competência do mediador. Este tem que ter capacidade para resolver a controvérsia, ou seja, ter as qualificações mínimas para dar andamento e sustentabilidade ao trabalho. A experiência no mundo da criminalidade torna-se um diferencial nesse aspecto, uma vez que somente em função do reconhecimento dela os jovens tornaramse verdadeiramente acessíveis ao diálogo. Conforme salienta Six (2001), cada mediador atua como um diretor de cinema ou um maestro de orquestra, sendo importante na condução do processo, mas não tomando o lugar dos atores ou dos músicos a quem compreendem, infundem confiança, insuflam ritmo, criando uma espécie de sinergia suplementar e impulsionando-os a dar todo o seu talento. Esta é a dinâmica de atuação adotada pelos instrutores/mediadores e pela equipe técnica social durante as oficinas culturais. Devemos compreender, ainda, que as ações desenvolvidas junto aos jovens pela instituição socioeducativa se enquadram, geralmente, na perspectiva da mediação tradicional, considerando-os como sujeitos violadores dos direitos fundamentais. Nesse sentido, essas ações são diretivas e não admitem uma paridade real entre seus protagonistas. Se há diálogo entre as partes, este visa à disciplinização e docilização do aluno, embora este seja reconhecido no discurso da instituição como sujeito de direitos. Citemos mais um caso a fim de exemplificar nossas colocações:

Numa aula da oficina de grafite, representantes da equipe técnica e da direção da unidade se apresentaram aos jovens, propondo a discussão de algumas normas para o funcionamento do trabalho. O discurso "democrático" dos funcionários se caracterizou pela liberdade de os jovens votarem na melhor regra, sendo estas determinadas a priori e não verdadeiramente discutidas com os alunos. Nesse caso, os membros da instituição presentes teciam uma série de argumentos considerados coerentes em favor de sua posição e pressionavam os alunos a de- 
cidirem em favor dela. Uma das regras apreciadas foi a do uso do mp3 em sala de aula. Os representantes da unidade montaram um eficiente discurso sobre as interferências do aparelho no rendimento da aula e já concluíam pela resolução do não uso do equipamento, quando representantes da equipe técnica social do GCAR opinaram, explicando que o recurso da música é algo comum na cultura do grafite e estimula o processo de criação do jovem. Ao pontuar que nem mesmo os instrutores, conhecedores do assunto, tiveram oportunidade de se manifestar, a equipe técnica social do GCAR abriu espaço para que os primeiros confirmassem $\mathrm{o}$ argumento da equipe e incitassem os jovens a falar mais sobre o assunto. Todos foram unânimes em dizer que gostavam de ouvir música e preferiam fazê-lo durante as atividades, dando outro desfecho para o caso.

A dissimetria na relação é clara nesse exemplo, pois o aluno sente-se coagido e nunca à vontade para questionar os argumentos impostos. A mediação se estabeleceu na possibilidade de desconstruir o que determinamos como discurso instituído e realmente possibilitar uma consolidação legítima das normas, com o objetivo de que a opinião dos alunos tivesse o mesmo peso que a dos funcionários. Por instituído entendemos as relações que nascem originalmente numa aspiração coletiva e legítima, mas que se cristalizam nos mecanismos que instrumentam as instituições. Ou seja, tornam-se naturais e eternas, desvinculando-se das transformações e reivindicações que a coletividade reclama no processo histórico e passam a valer por si e em si, transformando-se em relações de dominação: "A dominação do instituído é fundamentada sobre o esquecimento de suas origens, sobre a naturalização das instituições. Produzidas pela história, acabam aparentemente como fixas e eternas, como algo dado, uma condição necessária e trans-histórica da vida das sociedades" (COIMBRA, 1995, p. 61). Estabelecer um canal de comunicação com os jovens é justamente suspender essa dissimetria inerente às relações já instituídas e estar de igual para igual com eles num processo de reinvenção e legitimação das normas, o que leva tanto o profissional quanto os jovens a buscarem outro posicionamento em face ao que já está supostamente determinado.

Se os projetos sociais baseados em ações culturais têm uma função educativa, esta se caracteriza, no plano da aprendizagem da cidadania e dos valores éticos e políticos, como uma ação sociopedagógica, para além do conteúdo artístico desenvolvido. As ações devem priorizar a garantia, consciência e a manutenção dos direitos fundamentais e dos deveres, num processo de empoderamento e conquista da autonomia de seus participantes. A mediação se legitima, consequentemente, como ferramenta educativa e como estratégia de abordagem, operacionalizada no plano da linguagem, dos estratos simbólicos dos sujeitos envolvidos. Sua eficácia consiste na capacidade de penetrar na realidade dos participantes, suspendendo as divergências e antagonismos, favorecendo a articulação de uma política comum de intercâmbio e fortalecimento de novas relações e experiências entre os atores e criando um verdadeiro espaço de interlocução e de trocas legítimas. Esse processo tende, igualmente, a se expandir e se disseminar, contribuindo para a renovação e o fortalecimento dos vínculos entre as diversas partes envolvidas, inclusive, as instituições e organizações mantenedoras do projeto. 
Em meio ao desenvolvimento das ações, pudemos observar, em função da autogestão e da mediação, o surgimento de um caldo propício à coemergência dos vetores analisadores e indicativos do plano coletivo, considerado o motor das relações estabelecidas. O analisador pode ser considerado "um acontecimento, dispositivo, indivíduo, ou prática que revele a dimensão impensada de uma estrutura social, colocando em evidência elementos antes não considerados influentes ou determinantes do que se julga estabelecido ou instituído." (PASSOS; BARROS, 2000, p. 73). O analisador é o elemento que torna evidente as contradições implícitas na lógica dos discursos da instituição, tornando visíveis as condições de sua determinação. A autogestão se torna, pela via do questionamento, desconstrução e reinvenção das normas, o elemento fundamental na elaboração de um dispositivo de intervenção no contexto das oficinas. "Por isso é que a autogestão é utilizada nas intervenções socioanalíticas como um dispositivo analisador, como um contra-projeto organizacional e pedagógico.” (COIMBRA, 1995, p. 64). É no sentido de se contrapor ao projeto pedagógico e organizacional instituído que o "contra-projeto" aplicado nas oficinas culturais possibilita a consolidação dos grupos em torno das atividades, pois: "um grupo só é grupo se estiver fundado na autogestão, o que implica a autodeterminação, a autocrítica e a autoanálise." (COIMBRA, 1995, p. 59).

A mediação gerou, pela abertura de um espaço dialógico renovado, a consolidação de um plano no qual as relações de poder entre os atores tornaram-se apreensíveis nos acontecimentos ali deflagrados. E é neste ponto que ela se tornou uma tecnologia valiosa para a prática do psicólogo no contexto da intervenção. Ela nos põe, no plano metodológico e no da interação com os jovens, em contato com a dimensão instituinte, ou seja, o plano realmente legitimador das relações de poder em jogo. Resignificando-as, num espaço dialógico e paritário, construímos novas possibilidades de atuação e de reinvenção permanente das normas e das relações em questão, pois o objetivo é o de possibilitar o advento do plano instituinte, equivalente, como nos aponta Coimbra (1995), aos desejos e necessidades frutos de uma aspiração coletiva que faz com que se criem novas normas. Daí, o surgimento dessas novas normas.

\section{A InTERVEnÇão E OS PROCESSOS COLETIVOS}

Não compreendemos instituição em sua estrutura material, como, por exemplo, no conjunto de suas instalações (estabelecimentos), ou em seu conjunto de estruturas jurídicas de função social específica, tais como a escola, o hospital, as empresas, associações (organizações). Definimos o termo "como certas formas de relações sociais, tomadas como gerais e que se instrumentam nas organizações e nas técnicas, sendo nelas produzidas, reproduzidas, transformadas e/ou subvertidas." (RODRIGUES; SOUZA, 1991, p. 42). Portanto, os projetos culturais e sociais se constituem no plano instituinte mediante o reconhecimento de seu cunho coletivo, materializando-se tanto nas respectivas organizações e estabelecimentos, quanto no desenvolvimento de suas práticas. Tornar evidente esse processo e as relações de poder nele implícitas, dentro de uma política de gestão participativa, constitui-se um dos objetivos das intervenções. As ações culturais, consideradas 
em sua proposição de direito fundamental, legitimam-se como uma demanda genuinamente coletiva, articulando-se em torno delas os demais direitos básicos e gerando, nas ações educativas empreendidas, o fortalecimento de laços cidadãos.

A percepção dos atravessamentos históricos, políticos, sociais e culturais na determinação das relações estabelecidas, bem como o entendimento de que estes norteiam verdadeiramente as ações no âmbito das instituições tornam-se os componentes da intervenção. A rede social de trocas estabelecida entre os alunos, os representantes do projeto e os funcionários do DEGASE procurou a todo o momento dar passagem a essas forças. Durante as atividades das oficinas culturais, a mediação proporcionou um questionamento legítimo das normas instituídas, estimulando sua reinvenção mediante a proporcional autonomização e instrumentalização política dos alunos, em prol da defesa dos seus direitos fundamentais. Ao dispor aos jovens em cumprimento de medida socioeducativa, elementos que os estimulassem a transformar sua visão de mundo e a se tornarem protagonistas nas decisões tomadas no âmbito das oficinas, a intervenção passou a lhes instrumentalizar e implicar na luta pela manutenção de seus direitos. Consolidados no fortalecimento da rede de relações, esses vetores passaram a interferir diretamente na tessitura das instituições envolvidas, tornando-se o objeto da intervenção, que passa a não estar focada exclusivamente na ação do técnico nem ser unicamente por ele conduzida, mas balizada na participação de todos os atores envolvidos, de acordo com a metodologia proposta na observação dos analisadores institucionais como eixo fundamental da intervenção, tal como indicado por Passos e Barros (2000).

Se, no âmbito das oficinas culturais, os analisadores materializam-se nos acontecimentos potencializados pelas atividades, torna-se necessária a consolidação de um plano legitimamente propício à sua emergência, o que é garantido pelas ações mediadoras. Daí a valorização da participação diferenciada dos profissionais, não só na etapa de planejamento, mas no dia a dia do trabalho, inseridos diretamente nas atividades do projeto e abandonando uma suposta neutralidade. A identificação dos analisadores se opera mediante a implicação de todos os atores envolvidos. O técnico se coloca na condição de mais um, de uma singularidade dentre as outras, atuando para fortalecer e dar passagem às forças componentes das relações de poder em jogo. As atividades artísticas oferecidas, por possuírem a característica de aglutinar direta ou indiretamente todos os envolvidos no trabalho, transformam-se num momento propício às intervenções, ampliando, na rede de trocas estabelecidas entre os sujeitos, seus horizontes e seu alcance. Isso significa que a atuação do psicólogo deixa de estar atrelada aos formalismos protocolares do atendimento individual e da observação imparcial, passando a interagir dinâmica e diretamente com os grupos nas atividades. Não se observa o trabalho de fora. O técnico passa à condição de aluno, colocando-se em igualdade com ele num regime paritário, condição imprescindível para a consolidação da rede e para a interação com os demais atores, potencializando-se a produção de um espaço de coletivização. Consequentemente, a intervenção e a mediação passam a não priorizar somente os conflitos entre as partes ou grupos determinados. Elas deixam de se voltar somente às situações conflitantes, buscando antes, focalizar nas forças determinantes das relações sociais instituídas, a potência instituinte que 
lhes fundamenta. A função mediadora torna-se, nesse caso, aplicável ou exercida por todos os atores, sem centralizar-se na figura do instrutor ou do técnico, embora estes exerçam formalmente o papel de coordenação e condução do trabalho. Mas isso tende a se diluir num estado mínimo a assegurar o funcionamento do dispositivo, uma vez que a proposta é a de todos sejam, na medida do possível, gestores das atividades, contribuindo para a tomada de decisões, num circuito de trocas e de crescente autonomização, protagonismo e empoderamento.

E no seio desse dispositivo de intervenção, que usa do recurso da mediação como facilitador dos processos coletivos, a clínica passa a conotar novas significações, configurando-se, na dimensão da intervenção, como experiência de desvio, de deriva dos pontos de direção pré-estabelecidos ou instituídos. De acordo com o sentido da sua terminologia de origem, "klinamen," a clínica é pensada no sentido daquilo que faz bifurcar um percurso de vida na criação de novos territórios existenciais; uma clínica como valorização da produção de novas formas de existencialização e de produção de subjetividades. Por conseguinte, a atuação clínica no âmbito das oficinas culturais se esvazia de uma dimensão de atendimento individual, buscando, através da rede de relações estabelecidas e por meio do processo de mediação, levar os sujeitos a um vetor de bifurcação de suas próprias experiências, relativizando-as e ao mesmo tempo estimulando a reinvenção das normas instituídas mediante a abertura ao plano instituinte. Os atores se desviam da pseudofacticidade inerente ao determinismo implícito na lógica tradicional das relações impostas e têm com isso a possibilidade de criar novas maneiras de perceber e sentir o mundo e a si mesmos.

De acordo com Passos e Barros (2003), "o caráter híbrido das estratégias de intervenção está exatamente no ponto onde a solução de problemas convoca seu rearranjo, a invenção de um novo território onde tal problema será necessariamente outro. A solução de um problema se confunde com a criação de outro problema" (PASSOS; BARROS, 2003, p. 84). Se a intervenção preconiza a solução/criação de problemas, estes se materializaram na práxis cotidiana dos jovens durante as oficinas, a princípio, nas situações conflitantes emergentes na rede de relações como objeto da mediação. Mas, no decorrer das ações, os problemas já não se manifestavam tanto no aspecto das polarizações, ou dos contornos que os conflitos assumiam, quando percebidos e incorporados, por exemplo, como divergentes ou contrários aos interesses das partes. Na construção da rede dialógica e autogestora o campo problemático passa a ser percebido de maneira diferenciada como elemento constitutivo das próprias relações. Ou seja: em se tratando do campo mediador, o problemático e o conflitante se confundem. A intervenção nunca visa a destituir a força dessas duas nuances, consideradas como motriz de todo o processo, mas busca geri-las pela manutenção da rede, no entendimento de que elas passam a equivaler ao plano instituinte. Daí, a abertura ao campo impele a própria reinvenção das normas, dos modelos, estereótipos e representações naturalizadas, num movimento de ressingularização de si e do mundo. Longe da necessidade de acabar com os conflitos, a gestão coletiva procura validá-los em sua dimensão instituinte e fundante, utilizando-se do dispositivo de mediação a fim de que estes sejam absorvidos e geridos democrática e participativamente 
pela rede. Tal afirmação indica que consideramos o plano conflitante/instituinte/ problemático como fundamento das relações em questão. Fazer clínica é, desse modo, possibilitar experiências de desvio no conflito; uma operação desviante dada no encontro com o não estabelecido, abrindo, paradoxalmente, segundo a inspiração dos autores, um campo problemático de solução de problemas.

\section{Concluindo}

Durante a realização do projeto, tivemos a oportunidade de proporcionar a nós e aos alunos novas experiências de enriquecimento, por meio de uma rede de gestão dos processos coletivos construída durante a realização das oficinas culturais. A abertura de um canal direto de comunicação com os jovens em cumprimento de medida socioeducativa através da mediação possibilitou a criação de novas lentes, novos olhares dos jovens para si e para sua realidade, modificando, substancialmente, suas referências, posições e crenças quanto à opção pelo ato infracional e pelo crime. O respeito ao trabalho do GCAR, que "fecha com os jovens," justifica-se no estreitamento desses vínculos, fortalecendo a proposta da formação de multiplicadores.

A experiência obtida pelo "Projeto Oficinas Culturais do AfroReggae no Degase" não tem, certamente, a pretensão de afirmar a mediação de conflitos como a única estratégia de intervenção. As estratégias são livres e se constituem de acordo com as particularidades de cada contexto, podendo-se utilizar qualquer outro instrumento, tecnologia ou recurso, de acordo com cada experiência. Antes, a mediação nos serviu de estímulo à reflexão sobre os possíveis lugares do psicólogo no trabalho com jovens e adolescentes em conflito com a lei, demonstrando que a inserção desse profissional pode ocorrer de maneira criativa e implicada diretamente nos acontecimentos sobre os quais ela deveria se inclinar no sentido do klinos. Gerar uma rede de participação coletiva no contexto das oficinas culturais realizadas no DEGASE possibilitou tornar viável, perceptível e apreensível, para os jovens internos, o plano instituinte como legitimizador das relações de poder em jogo.

Há de se considerar o caráter transitório relativo às normas estabelecidas no contexto das oficinas culturais, além do problema da existência do plano instituído manifesto nas regras a serem obrigatoriamente obedecidas no âmbito da instituição, principalmente, pelos jovens. A dimensão instituinte seria assim, secundária e transitória em relação às normas instituídas, uma vez que esta só teria sentido no espaço das oficinas, voltando o jovem à rotina docilizada das regras instituídas e inculcadas, após as atividades. Essa discussão nos leva à questão da liberdade como condição de possibilidade de reinventar e transformar as normas e nos impele a discutir o conceito de sobreimplicação. Se a implicação se refere à condição de sermos atravessados querendo ou não pelas instituições, tal como nos aponta Monceau (2008), a sobreimplicação revela um impasse dado na impossibilidade de analisar a implicação, isto é, de analisar a tessitura desses atravessamentos. "O conceito [...] poderia ser definido como uma impossibilidade de analisar a implicação" (MONCEAU, 2008, p. 23). 
Devemos lembrar que o contexto da instituição socioeducativa, marcado pelas adversidades anteriormente relatadas, seja de fato hostil a uma proposta autogestiva. Entretanto, no caso dos jovens, a condição de privação de liberdade e de estarem submetidos a regras estritamente verticalizadas seria impedimento para que estes pudessem pensar as relações ali estabelecidas e reinventar normas? Submetermo-nos a regras instituídas (e nos submetemos a muitas) nos impossibilita pensá-las e mesmo transformá-las? Se existe uma transitoriedade relativa ao plano instituinte pensada no limite do espaço, do tempo e das condições dos jovens reinventarem suas práticas por meio do trabalho cultural, devemos considerar que exista também uma transitoriedade em relação ao plano instituído e ao signo mais imediato de sua concretude para o jovem: a privação da liberdade. A subjetividade no contexto desses atores, embora capturada e violentada pelas injunções disciplinares da instituição, não se limita à rotina socioeducativa, não fica contida em uma cela e não deixa de produzir algo novo. Nesse sentido, não deixa de escapar à dominação e ser livre. O trabalho cultural visa a investir nessa possibilidade de liberdade, a fim de transpor os limites do encarceramento, criando desvios, linhas de fuga diante dos limites impostos pelo instituído.

Tal fato propiciou aos alunos se sentirem mais íntimos da dimensão instituinte, vilipendiada pelos engessamentos das relações institucionalizadas. $\mathrm{O}$ dispositivo de intervenção, baseado numa proposta autogestiva e na mediação, fez com que esse plano se tornasse acessível nos processos decisórios protagonizados pelos jovens. O principal ganho obtido pelas ações empreendidas foi o de proporcionar às vítimas da violência e da coerção no sistema socioeducativo, sejam jovens ou mesmo funcionários, instrumentos para que pudessem, eles mesmos e em conjunto com as ações desenvolvidas, lutar por condições mais dignas de vida, reivindicando-as. Daí, o compromisso ético em definir o plano político, numa proposta de manutenção dos direitos humanos, como prioridade.

O panorama atual, no qual se situa o Departamento de Ações Socioeducativas, seu vínculo com a Secretaria de Estado de Educação e a parceria com o Grupo Cultural AfroReggae, possibilitou o equacionamento de uma sinergia sem precedentes no planejamento de políticas de atenção aos jovens em conflito com a lei. O projeto constituiu-se uma ação inovadora e demonstrativa de que a soma e a ampliação dos esforços das instituições e da sociedade como um todo podem gerar resultados mais efetivos no enfrentamento deste problema. A participação das organizações não governamentais no planejamento de políticas públicas de atenção e cuidado voltadas para o sistema socioeducativo alimenta novos debates sobre o tema. Elas podem contribuir para a criação de novas políticas de atendimento para os jovens em cumprimento de medida socioeducativa e para o desenvolvimento de novas abordagens verdadeiramente sensíveis à sua realidade social e cultural. Nesse ponto, a prática do psicólogo deve ser objeto de reflexão e reinvenção constantes. 


\section{Notas}

${ }^{1}$ Rauter reitera sobre o tema que "seria necessário impedir a reprodução quotidiana dos estigmas institucionais, fundados na crença de que trabalhar com infratores e anti-sociais de todo gênero é impor limites coercitivos (RAUTER, 2003, p. 6). Para Misse, a "sujeição criminal é um processo de criminação de sujeitos, e não de cursos de ação. Trata-se de um sujeito que "carrega" o crime em sua própria alma; não é alguém que comete crimes, mas que sempre cometerá crimes, um bandido, um sujeito perigoso, um sujeito irrecuperável, alguém que se pode desejar naturalmente que morra; que pode ser morto, que seja matável. No limite da sujeição criminal, o sujeito criminoso é aquele que pode ser morto". (MISSE, 2010, p. 21).

${ }^{2}$ Segundo autora, a maioria da população lotada nas suas unidades de internação é composta por jovens negros do sexo masculino, que não completaram o ensino fundamental e que pertencem a núcleos familiares cuja renda não chega a dois salários mínimos. Ver ROCHA (2002).

${ }^{3}$ Barros afirma durante a abertura de mesa redonda no seminário nacional sobre a atuação dos psicólogos junto aos adolescentes privados de liberdade: "É claro que todo este contexto, na maioria das vezes, está permeado por condições de trabalho inóspitas e apresenta inúmeras dificuldades para acreditarmos na construção de um projeto socioeducativo, com pouca referenciação técnica e delimitação do que o psicólogo deveria fazer." (BARROS; WAISELFISZ; ROSENO, 2006 p. 42).

${ }^{4}$ Foucault ao definir o conceito de disciplina coloca que: "ela é um tipo de poder, uma modalidade para exercê-lo, que comporta todo um conjunto de instrumentos, de técnicas, de procedimentos de níveis de aplicação de alvos; ela é uma 'física' ou uma 'anatomia' do poder, uma tecnologia" (FOUCAULT, 1975, p. 177). Essa tecnologia se aplica no sentido da dominação como uma vertente de exclusão e é muito evidente nos mecanismos da instituição socioeducativa, tais como o sistema de recompensas e punições utilizadas na gestão do bom comportamento: "A disciplina recompensa unicamente pelo jogo das promoções que permitem hierarquias e lugares; pune rebaixando e degradando" (FOUCAULT, 1975, p. 151). Segundo Goffman, podemos considerar o assujeitamento, a despersonalização e a exclusão como presentes ao processo de mutilação do eu, aqui entendido como desconstrução das referências e da identidade pela submissão ao fausto dos mecanismos (disciplinares) das instituições: "Numa instituição total, no entanto, os menores segmentos da atividade de uma pessoa podem estar sujeitos a regulamentos e julgamentos da equipe diretora; a vida do internado é constantemente penetrada pela interação de sanção vinda de cima [...]. Cada especificação tira do indivíduo uma oportunidade para equilibrar suas necessidades e seus objetivos de maneira pessoalmente eficiente e coloca suas ações a mercê de sanções. Violenta-se a autonomia do ato" (GOFFMAN, 1961, p. 42).

\section{REFERÊNCIAS}

BARROS. M, WAISELFISZ, J. J.; ROSENO, R. Subsídios para a construção de uma prática qualificada do psicólogo no atendimento ao adolescente em privação de liberdade. In: COMISSÃO NACIONAL DE DIREITOS HUMANOS CFP, \& COMISSÃO NACIONAL DE DIREITOS HUMANOS do CONSELHO FEDERAL DA OAB. 2006, Brasília. Relatório do Seminário Nacional a Atuação dos Psicólogo Junto aos Adolescentes Privados de Liberdade. Brasília, 2006, p. 41-43.

BRASIL. Estatuto da Criança e do Adolescente. 3. ed. Brasília: MS, 2007.

CASTRO, A. L. S.; GUARESCHI, P. Da privação da dignidade social à privação da liberdade individual. Psicologia \& Sociedade, Porto Alegre, v. 20, n. 2, p. 200-207, 2008. 
COIMBRA, C. M. B. Os caminhos de Lapassade e da análise institucional: uma empresa possível? Revista do Departamento de Psicologia - UFF, Niterói v. 7 , n. 1, p. 52-80, 1995.

CONSELHO NACIONAL DOS DIREITOS DA CRIANÇA E DO ADOLESCENTE. Sistema Nacional de Atendimento Socioeducativo-SINASE. Brasília, 2006, p. 25-34.

CUNHA, M. S., SALES, R.; CANARIM, C. O movimento MOLEQUE: movimento de mães pelos direitos dos adolescentes no sistema socioeducativo. In: COMISSÃO DE DIREITOS HUMANOS DO CRP-RJ . Direitos Humanos? O Que Temos a Ver Com Isso? Rio de Janeiro: Conselho Regional de Psicologia RJ, 2007. p. 25-48.

DA MATTA, A. Relativizando: uma introdução à antropologia social. Rio de Janeiro: Rocco, 1999.

ESPÍNDULA, D. H. P.; SANTOS, M. F. S. Representações sociais sobre a adolescência a partir da ótica dos educadores sociais de adolescentes em conflito com a lei. Psicologia em Estudo, Maringá, v. 9, n. 3, p. 357-367, 2004.

FOUCAULT, M. Vigiar e punir: historia da violência nas prisões. Rio de Janeiro: Vozes, 1975.

GOFFMAN, E. Manicômios, Prisões e Conventos. São Paulo: Perspectiva, 1961.

LIMA, R. S. de. Atributos raciais no funcionamento do sistema de justiça criminal paulista. São Paulo em Perspectiva, São Paulo, v. 18, n.1, p. 60-65, 2004.

LOURAU, R. A Análise Institucional. Rio de Janeiro: Vozes, 1970.

MEIRELLES, Z. V.; GOMEZ, C. M. Rompendo com a criminalidade: saída de jovens do tráfico de drogas em favelas da cidade do Rio de Janeiro. Ciência e Saúde Coletiva, Rio de Janeiro, v.14, n.5, p. 1797-1805, 2009.

MISSE, M. Crime, sujeito e sujeição criminal: aspectos de uma contribuição analítica sobre a categoria “bandido”. Lua Nova, São Paulo, v. 79, n. 1, p. 15-38, 2010 .

MONCEAU, G. Implicação, sobreimplicação e Implicação profissional. Fractal Revista de Psicologia, Niterói, v. 20, n.1. p. 19-26, 2008.

MOORE, C. W. O Processo de Mediação. Porto Alegre: Artmed, 2002. 
PASSOS, E.; BARROS, R. B. A construção do plano da clínica e o conceito de transdisciplinaridade. Psicologia: Teoria e Pesquisa, Brasília, v. 16, n. 1, p. 7179, 2000.

PASSOS, E.; BARROS, R. B. Complexidade, transdisciplinaridade e produção de subjetividade. In: FONSECA, T. M. G.; GOMES, P. (Org.). Cartografias e Devires. A Construção do Presente. Porto Alegre: UFRGS, 2003, p. 81-89.

RAMOS, S. Respostas brasileiras à violência e novas mediações: o caso do Grupo Cultural AfroReggae e a experiência do projeto Juventude e Polícia. Ciência e Saúde Coletiva, Rio de Janeiro, v.11, Supl, p. 1303-1311, 2007.

RAUTER, C. Produção social do negativo: notas introdutórias. In: ENCONTRO MUNDIAL DOS ESTADOS GERAIS DA PSICANÁLISE, 2., 2003, Rio de Janeiro, Anais... Rio de Janeiro, 2003, p. 03-19.

ROCHA, E. Mapeamento Nacional da Situação das Unidades de Execução da Medida Socioeducativa de Privação de Liberdade ao Adolescente em Conflito com a Lei. Brasília: IPEA/DCA-MJ, 2002.

RODRIGUES, H. B. C.; SOUZA, V. L. B. de. A análise institucional e a profissionalização do psicólogo. In: SAIDON, O.; KAMKHAGI, V. R. K. Análise Institucional no Brasil. Rio de Janeiro: Rosa dos Tempos, 1991. p. 27-46.

SILVA, E. R. A.; GUERESI, S. Adolescentes em conflito com a lei: situação do atendimento institucional no Brasil. Brasília: IPEA, 2003.

SIX, J. F. Dinâmica da Mediação. Belo Horizonte: Del Rey, 2001.

SOARES, F. M; RIBEIRO, L. M. F; DUARTE, D. E. T. Caderno do Projeto Oficinas Culturais do AfroReggae no DEGASE.. Rio de Janeiro: Graffin, 2009. Relatório.

ZALUAR, A. Gangues, galeras e quadrilhas: globalização, juventude e violência. In: VIANNA, H. Galeras Cariocas. Território de Conflitos e Confrontos Sociais. Rio de Janeiro: UFRJ, 1997. p. 17-57.

Recebido em: fevereiro de 2010 Aceito em: outubro de 2010 